\title{
Present status and prospects of magnetite nanoparticles-based hyperthermia
}

\author{
Balachandran JEYADEVAN ${ }^{\dagger}$ \\ Department of Material Science, School of Engineering, The University of Shiga Prefecture, \\ 2500 Hassaka-cho, Hikone-City, Shiga 522-8533
}

\begin{abstract}
Magnetic fluid hyperthermia is a cancer treatment technique that utilizes the heat dissipated by magnetic nanoparticles exposed to an alternating current magnetic field. The heat dissipated is consequence of the conversion of the magnetic energy through different relaxation mechanisms, which depends on the physical properties of the magnetic particles. Particularly, in the case of magnetic nanoparticles, the magnetic energy is converted to heat energy either by the resistive response of the rotation of the magnetic particles (Brownian relaxation) or the rotation of the magnetic moment within the particles (Néel relaxation) to the alternating magnetic field. In this article, the main focus has been on the progress of theoretical and experimental investigations towards the realization of magnetic fluid hyperthermia (MFH) through heat dissipation by Néel relaxation of magnetite particles. We discuss about the present status and prospects of magnetite nanoparticles-based hyperthermia focusing mainly on the dissipation of heat through Néel relaxation mechanism. In doing so, an attempt has been made to review and deepen the understanding on specific topics such as (a) specific heat absorption characteristics of magnetite, especially the physical properties of particles that generate heat through Néel relaxation, (b) the preparation techniques available to synthesize particles with required properties, (c) experimental investigations carried out to determine the relative contribution of Néel relaxation to dissipate heat and their potential for in vivo application, and (d) the theoretical estimation of and experimental verification of heat diffusion characteristics of magnetite. The theoretical and experimental studies have suggested that the development of case specific treatment technologies based on an integrated approach considering both the physical constraints of the magnetic particles to be used as thermal seeds and practically feasible alternating magnetic field generators is a must for the establishment of MFH therapy in the foreseeable future.
\end{abstract}

(C)2010 The Ceramic Society of Japan. All rights reserved.

Key-words : Magnetic hyperthermia, Magnetite, Néel relaxation, Brownian relaxation, Heat diffusion, Heat dissipation

[Received March 8, 2010]

\section{Introduction}

Magnetic hyperthermia is a technique that proposes the annihilation of cancer cells through the elevation of cell temperature above $316 \mathrm{~K}$ by utilizing the heat dissipated by magnetic particles exposed to an alternating magnetic field. ${ }^{1), 2)}$ The magnetic heating phenomenon is a consequence of the response of magnetic particles exposed to an alternating current (AC) magnetic field that converts the magnetic energy into heat energy. For example, when a magnetic field of strength larger than the coercive force of a particle is applied in the direction opposite to the magnetic moment within the particle, the forced reversal of the magnetic moment occurs and Zeeman energy will be dissipated to the surroundings. Though the magnetic heating phenomenon has been proposed and experimentally verified even more than 50 years ago, ${ }^{3), 4)}$ over the last 10 to 15 years the field of magnetic particle hyperthermia has been revitalized with the introduction of magnetic entities that are nearly superparamagnetic compared to ferromagnetic in the earlier case. ${ }^{5)-15)}$ As a consequence, the researches on studies developing potential thermal seeds have dominated and a common consensus has been arrived at using magnetite nanoparticles for the above application largely due to their ability in performing tasks other than heat dissipation such as drug delivery on one hand, and also operating within the practical constraints of the magnetic field generators

\footnotetext{
$\dagger$ Corresponding author: B. Jeyadevan; E-mail: jeyadevan.b@mat. usp.ac.jp
}

on the other. However, it should be noted that for effective magnetic fluid hyperthermia (MFH) treatment, research in the fields of synthesis of monodispersed magnetite particle, their heat dissipation and diffusion characteristics and formulation of case specific strategies are vital. In this article, an attempt has been made to review and deepen our understanding on the present status of magnetite nanoparticle-based hyperthermia with respect to heat dissipation and diffusion characteristics by focusing our attention to studies related to (a) specific heat absorption characteristics of magnetite, especially the physical properties of the particles that generate heat through Néel relaxation, (b) possible synthesis techniques available to cater the nanoparticles needed for such application, (c) experimental investigations to determine the relative contribution of Néel relaxation to heat dissipation and their potential for in vitro applications, and (d) the theoretical estimation and experimental verification of heat diffusion characteristics of magnetite particles.

\section{Relaxation mechanisms and heat dissipation through Néel relaxation}

When the particles are in the nanometer size range, the magnetic vectors in these particles vibrate and will not stay static in the metastable state. Furthermore, when these particles are dispersed in a low viscous solvent, in addition to the spin rotation, the reversal of the magnetic vector through particle rotation also has to be considered. However, even in free reversal through spin rotation system, if the magnetic field alteration is realized at relatively very shorter times, the magnetic vector is 


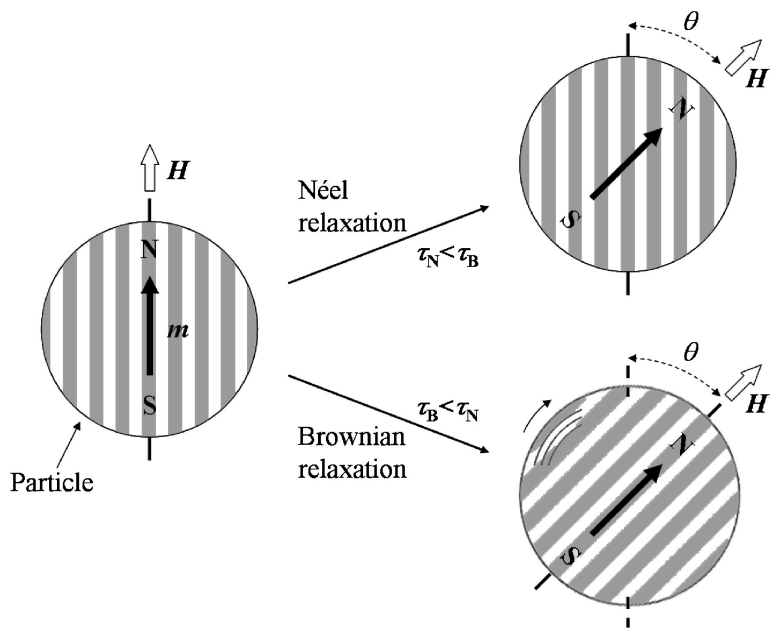

Fig. 1. The rotation of magnetic moment in nanoparticles. The relaxation of the magnetic moment is realized either through Néel or Brownian relaxations. Magnetic moment rotates via Néel relaxation when the measuring temperature is above the blocking temperature and the measuring time is longer than the relaxation time. Magnetic moment rotates through Brownian relaxation when the measuring temperature is less than the blocking temperature and the measuring time is shorter than relaxation time.

unable to respond quickly enough and consequently the magnetic energy is dissipated as heat. And also, in higher viscous liquids, particles could dissipate heat through forced rotation due to magnetic torque under strong magnetic fields. The schematic representations of relaxations of magnetic vector either through spin rotation (Néel) or particle rotation (Brownian), when the particles are exposed to an AC magnetic field with different magnetic field reversal times are shown in Fig. 1.

The Néel $\left(\tau_{\mathrm{N}}\right)$ and Brownian $\left(\tau_{\mathrm{B}}\right)$ magnetic relaxation times of particles are given by the following equations.

$$
\begin{aligned}
& \tau_{\mathrm{N}}=\frac{\pi^{1 / 2}}{2} \tau_{0} \frac{\exp \Gamma}{\Gamma^{1 / 2}} \\
& \Gamma=\frac{K V_{\mathrm{M}}}{k T} \\
& \tau_{\mathrm{B}}=\frac{3 \eta V_{\mathrm{H}}}{k T} \\
& \tau=\frac{\tau_{\mathrm{B}} \tau_{\mathrm{N}}}{\tau_{\mathrm{B}}+\tau_{\mathrm{N}}}
\end{aligned}
$$

Where, $\tau_{\mathrm{N}}$ : Néel relaxation time, $\tau_{\mathrm{B}}$ : Brown relaxation time $\tau$ : effective relaxation time, $\tau_{0}=10^{-9}$ [sec], $K$ : anisotropy constant, $V_{\mathrm{M}}$ : volume of particle, $k$ : Boltzmann constant, $T$ : temperature, $\eta$ : viscosity, $V_{\mathrm{H}}$ : hydrodynamic volume of particle.

As stated above, the heat dissipated by magnetic particles, depend on the rotation mechanisms, such as, Néel or Brownian relaxations. And also, depending on the driving force, the mechanism could be divided into superparamagnetic and magnetic field imposed forced reversal and rotation. Here, let us consider the possible magnetic heat dissipation mechanisms operable in the case of nearly superparamagnetic magnetite nanoparticles. From the above equations, it is obvious that the relaxation time relies on the particle diameter. The relationship between particle diameter of magnetite, which is used in this study, and relaxation time is given in Fig. 2. The magnetic moment relaxes through Néel relaxation when the particle diameter is less than $13 \mathrm{~nm}$. And the particles with diameter $14 \mathrm{~nm}$ or above relax through Brownian relaxation, at room

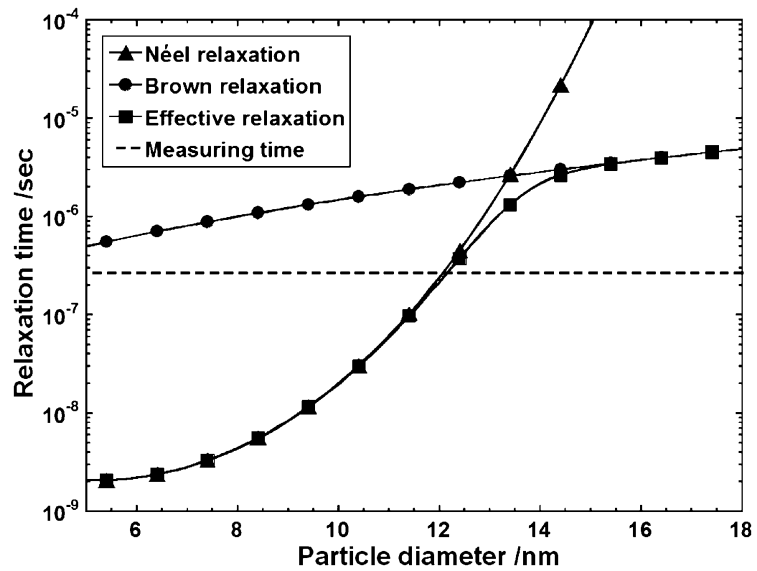

Fig. 2. Characteristic relaxation times of magnetic moment as a function of particle diameter. The calculations were based on the following data: Surfactant layer thickness: $3.2 \mathrm{~nm}$, anisotropy constant of magnetite: $30 \mathrm{~kJ} \mathrm{~m}^{-3}$, measurement temperature: $300 \mathrm{~K}$, viscosity: $0.00089 \mathrm{~kg} \mathrm{~m}^{-1} \mathrm{~s}^{-1}$, Frequency (measuring time): $600 \mathrm{kHz}$.

temperature (R.T.). Generally, the magnetic suspension available in the market has a very wide particle size distribution. Thus, when these suspensions are exposed to an AC magnetic field with magnetic reversal time less than the magnetic relaxation time of the particle; heat is dissipated due to the delay in the relaxation of the magnetic moment through spin rotation and particle rotation. Thus, the heat dissipation value is calculated using the harmonic average of both relaxations (Eq. (4)) and their relative contributions depend on the particle diameter. The equation of heat dissipation is given by the following. ${ }^{16)}$

$$
P=\mu_{0} \chi^{\prime \prime} f H_{\text {applied }}^{2}
$$

$P$ : Heat dissipation value, $\mu_{0}$ : permeability of free space, $\chi^{\prime \prime}: \mathrm{AC}$ magnetic susceptibility (imaginary part), $f$ : frequency of applied AC magnetic field, $H_{\text {applied: }}$ strength of AC magnetic field.

As it can be seen from the equation, the heat dissipated is proportional to the frequency and square of magnetic field strength. At present, the magnitude of heat dissipation is represented as the specific heat absorption rate (SAR), i.e. $\mathrm{W} \mathrm{g}^{-1}$, the derivation of which does not take the magnetic field strength and frequency values into consideration. Thus the true potential of thermal seeds cannot be judged from the SAR values alone. Consequently, the author proposed the use of effective specific absorption rate (ESAR) values that were calculated using the equation given below taking the magnetic field strength and frequency into consideration. ${ }^{17)}$ Theoretical estimation of ESAR values as a function of particle diameter (maximum of $18 \mathrm{~nm}$ ), assuming a harmonic mean value for the relaxation time of $2.6 \times 10^{-7} \mathrm{~s}$ is calculated according to Eq. (6):

$$
\text { ESAR }=\frac{\sum_{i} c_{i} m_{i}}{m_{\mathrm{Fe}_{3} \mathrm{O}_{4}}} \frac{\Delta T}{\Delta t} \frac{1}{H_{\text {applied }}^{2} f}
$$

$c$ : specific heat, $m_{i}$ : mass of each particle, $m_{\mathrm{Fe}_{3} \mathrm{O}_{4}}$ : mass of magnetite nanoparticle, $T$ : temperature, $t$ : time, $f$ : frequency of

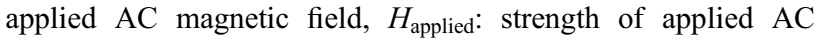
magnetic field.

Figure 3 shows ESAR as a function of magnetite particle diameter. The area under the curve represents the total heat dissipated through Néel as well as Brownian relaxations. On the 


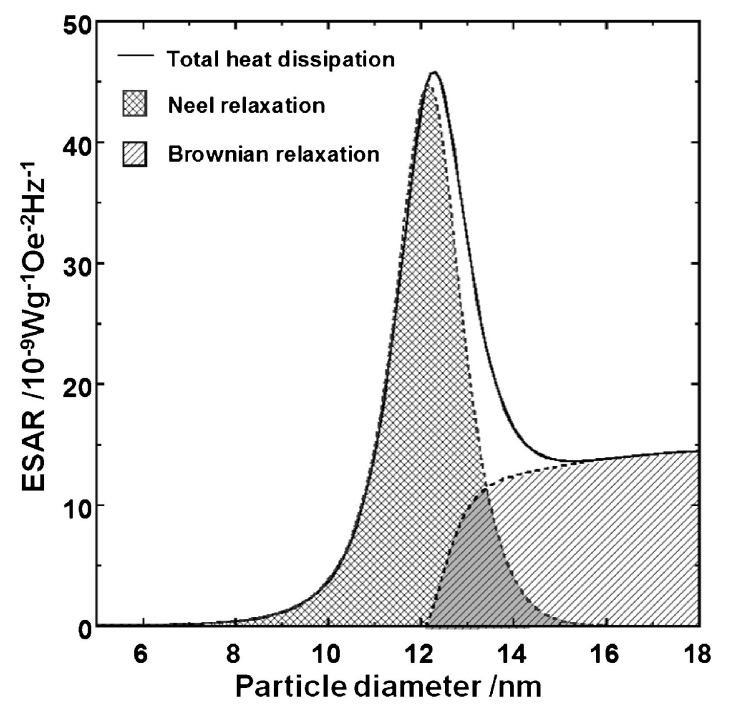

Fig. 3. Theoretical heat dissipation by Néel and Brownian relaxation in water. $f=600 \mathrm{kHz}, H_{\text {applied }}=40(\mathrm{Oe}), T=300(\mathrm{~K}), \eta=0.89(\mathrm{mPa} \cdot \mathrm{s})$, $M_{\mathrm{s}}=5.6(\mathrm{kOe}), K=30\left(\mathrm{~kJ} \mathrm{~m}^{-3}\right)$, specific heat $=670\left(\mathrm{~J} \mathrm{~kg}^{-1} \mathrm{~K}^{-1}\right)$, density $=5180\left(\mathrm{~kg} \mathrm{~m}^{-3}\right)$, concentration of magnetite nanoparticles $=4.0$ (mass\%). ESAR: Effective specific absorption rate.

other hand, the heat dissipated by Néel relaxation alone is represented by the mesh textured area. Thus depending on the particle size distribution, the relative contribution from Néel and Brownian relaxations will vary. It should be noted that the heat dissipated through Néel relaxation is not influenced by the local condition of the particle dispersed in any medium.

On the other hand, the heat dissipated by Brownian relaxation will be influenced very much by the local environment surrounding the particles. For example, if the viscosity of the medium in which these particles are dispersed is high or if the freedom of rotation is suppressed, the heat dissipated by these particles through Brownian relaxation will either diminish or stop. Thus, to realize similar ESAR values in vitro and in vivo experiments; it is essential to have particles that relax through Néel mechanism. Though the sizes of particles that could dissipate heat through the Néel and Brownian motion of the magnetic vector can be estimated theoretically, ${ }^{16)}$ their relevant contribution in any samples for magnetic hyperthermia or the concept towards practical application has not been given due consideration. In the practical sense, relative contributions of Néel and Brownian relaxations to heat dissipation in any sample should be verified as the local environment within the cell may influence the Brownian contribution and the heat dissipated could become less than the anticipated values. The above concept has been experimentally verified recently ${ }^{18)}$ and stresses the importance of detailed analysis of relative contribution for effective therapy.

As already known, if we were to utilize the Néel relaxation at low magnetic field range, the conditions under which large amount of heat could be anticipated depends very much on the size of the particle. This is due to the exponential dependence of relaxation time on size sensitive anisotropy energy. On the other hand, if we were to use strong magnetic field region, the condition for heat dissipation generally depends on the coercive force $H_{c} \sim 0.96 H_{k}$ (anisotropic field) and the influence of particle diameter becomes negligible. Due to the disparity in properties caused by the difference in applied magnetic field strength, the use of forced magnetic reversal was considered advantages in cases where particle size control is poor, in contrast to the Néel

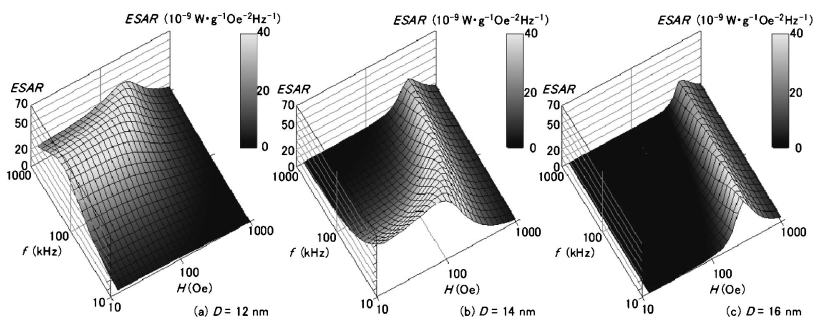

Fig. 4. Heat dissipation (ESAR) for the magnetite nanoparticles exposed to different magnetic field strengths and frequencies. The following conditions were used in the calculations: $M_{s}=446 \mathrm{emu} / \mathrm{cm}^{3}$, $K_{u}=300 \mathrm{kerg} / \mathrm{cm}^{3}, T=300 \mathrm{~K}, f_{0}=109 \mathrm{~s}^{-1}$.

relaxation case where monodispersed particles were a prerequisite. And in recent years, with the advent of magnetic particle synthesis techniques, the problems associated with magnetic heat dissipation through Néel relaxation using magnetite particles is making considerable progress,

To extract the optimum effect during hyperthermia treatment, particles that suit the magnetic field and frequency (ac magnetic field) conditions have to be designed. To do so, certain technological barriers have to be overcome. However, the fact that the cancer patients are awaiting the development of appropriate treatment techniques cannot be discarded. Therefore, for the time being, effective practical solutions using the already available magnetic nanoparticles should be considered. For example, decision whether the ac magnetic field generators should be designed with higher magnetic field strength or higher frequencies has to be made. Thus here 12, 14 and $16 \mathrm{~nm}$ magnetite particles with effective magnetic anisotropy energy of $30 \mathrm{~kJ} / \mathrm{m}^{3}\left(H_{k} 107 \mathrm{kA} / \mathrm{m}\right)$ are considered based on the recently reported experimental data ${ }^{17)}$ and their results are discussed. As stated above, since the Brownian relaxation is influenced mainly by the local conditions, heat dissipation through Néel relaxation alone is considered here.

Figure 4 shows the heat dissipation values for magnetite particles with diameters 12,14 and $16 \mathrm{~nm}$ as a function of magnetic field strengths and frequencies. In this figure, the Néel relaxation time under zero field for 12,14 and $16 \mathrm{~nm}$ particles are $0.7 \mu \mathrm{s}\left[\left(f_{\mathrm{N}}=2 \pi \tau_{\mathrm{N}}\right)^{-1}\right.$ about $\left.\left.227 \mathrm{kHz}\right)\right], 33 \mu \mathrm{s}\left[\left(f_{\mathrm{N}}=2 \pi \tau_{\mathrm{N}}\right)^{-1}\right.$ about $48 \mathrm{kHz})]$ and $5.6 \mathrm{~ms}\left(f_{\mathrm{N}}=2 \pi \tau_{\mathrm{N}}\right)^{-1}$ about $\left.28.6 \mathrm{kHz}\right)$, respectively. It should be noted that the variation in ESAR values depend on the frequencies and magnetic field strengths. And also, their dependence is a function of particle diameter. This suggests that the normalization of the heat dissipation with frequency and square of magnetic field strength does has its own limitations and the particle diameter considered for the comparison should also be considered for the rational evaluation of the results.

As shown above, the ac magnetic field conditions depend strongly on the particle diameter. Thus, discussion in the next section will be confined to the synthesis, magnetic and heat dissipating properties of magnetite nanoparticles.

\section{Synthesis of magnetite nanoparticles suitable for heat dissipation through Néel relaxation}

The extensive growth in activities associated with the potential use of magnetic nanoparticles in general and magnetite particles in specific biomedical applications has triggered research on synthetics routes for particles with well defined physical properties. It is well known that the size influences the specific absorption rates of magnetite and particles with sizes ranging between 40 (mono- to multi-domain transition) and $10 \mathrm{~nm}$ have 

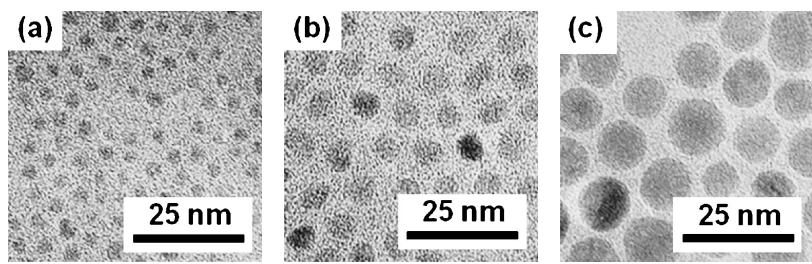

Fig. 5. The TEM images of magnetite particles with different diameters synthesized using thermal decomposition technique. ${ }^{26)}$
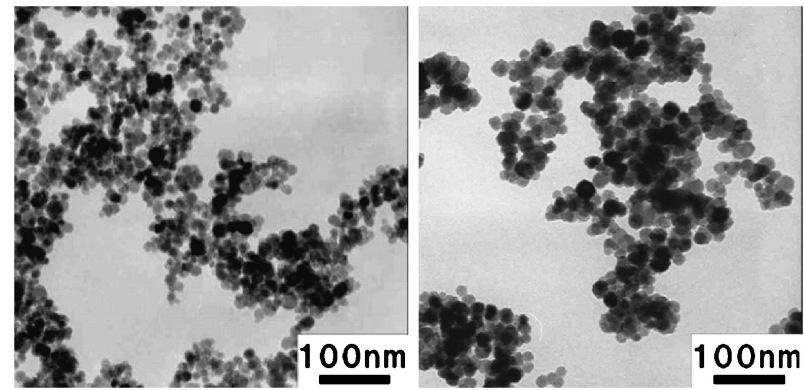

Fig. 6. Magnetite particles synthesized by modified oxidation technique.

been considered for magnetic hyperthermia. Although nanoparticles below $10 \mathrm{~nm}$ could be synthesized through conventional coprecipitation of divalent and trivalent iron ions in alkaline media $^{19)}$ and thermal decomposition of organometallic compounds, ${ }^{20)}$ and particles above $30 \mathrm{~nm}$ through oxidation methods $^{21), 22)}$ neither the synthesis nor the heating characteristics of magnetite particles in the intermediate size range has been investigated in detail. One of the main reasons for the above is the unavailability of the synthesis technology to produce magnetic nanoparticles (MNPs) with narrow size distribution in the range between 10 and $30 \mathrm{~nm}$. Hence the optimum parameters, such as average size, claimed by researchers vary widely and the comparison has become difficult. Author believe that any step forward towards resolving the above problems should begin with the development of a synthesis scheme to prepare MNPs with reasonably different magnetic properties. Though higher temperature decomposition of organic precursors has been claimed to produce monodispersed particles in a wide size range by manipulating the precursor, solvent and surfactant, ${ }^{23)-26)}$ as shown in Fig. 5, large-scale synthesis of magnetite particles in the above size range has been limited. In the case of oxidation method, though the synthesis of particles with sizes less than $30 \mathrm{~nm}$ are found to be difficult to achieve, some degree of control has been achieved by modifying the oxidation process through either introducing the oxidant, specific concentration of ferric ions at the beginning of the reaction, etc., ${ }^{27), 28)}$ as shown in Fig. 6. On the other hand, although particle sizes less than $10 \mathrm{~nm}$ could be commonly synthesized using coprecipitation technique, particles with diameter larger than $12 \mathrm{~nm}$ with narrower size distribution has been found difficult. ${ }^{29), 30)}$ Also, the fraction of particles with diameter smaller than $10 \mathrm{~nm}$ with lower heating capacity is considerably high due to poor control over the magnetite forming reaction. This could only be improved by finer control of the reaction $\mathrm{pH}$ which fluctuates drastically in the conventional method. Thus the author attempted the synthesis of magnetite particles by controlling the $\mathrm{pH}$ of the reactants by using $\mathrm{pH}$ stabilizing agents. The details of this technique are described below.

\section{1 pH stabilized coprecipitation technique}

In the conventional coprecipitation technique, the ferrous and ferric metal ions are introduced into a highly alkaline solution and the reaction progresses as indicated below.

$$
\begin{aligned}
\mathrm{Fe}^{2+}+2 \mathrm{Fe}^{3+}+8 \mathrm{OH}^{-} & \rightarrow \mathrm{Fe}(\mathrm{OH})_{2}+2 \mathrm{Fe}(\mathrm{OH})_{3} \\
& \rightarrow \mathrm{Fe}_{3} \mathrm{O}_{4}+4 \mathrm{H}_{2} \mathrm{O}
\end{aligned}
$$

As the mixed metal ion solution is introduced into sodium hydroxide solution, the $\mathrm{pH}$ of the suspension continues to vary from very high to low during the course of the formation of magnetite and stabilizes at around 12. This fluctuation in $\mathrm{pH}$ influences the concentration of metal complexes formed during the course of the reaction. Consequently, nucleation and growth rates also continue to fluctuate during the course of magnetite formation. As a result, the particles become highly polydispersed. Maintaining the $\mathrm{pH}$ constant at any specific value throughout the reaction would facilitate the control over the size and size distribution of magnetite.

In the case of ferrous ions, the concentrations of complex iron (II) species such as $\mathrm{Fe}^{2+},[\mathrm{Fe}(\mathrm{OH})]^{+}, \quad\left[\mathrm{Fe}(\mathrm{OH})_{3}\right]^{-}$ $\left[\left(\mathrm{Fe}^{2+}\right)\left(\mathrm{OH}^{-}\right)\right]^{+},\left[\left(\mathrm{Fe}^{2+}\right)\left(\mathrm{OH}^{-}\right)_{2}\right],\left[\left(\mathrm{Fe}^{2+}\right)\left(\mathrm{OH}^{-}\right)_{3}\right]^{-}$show drastic change with $\mathrm{pH}$ which is critical in the formation of magnetite particles. ${ }^{27)}$ The free ferrous ions begin to form hydroxyl ion complexes around $\mathrm{pH} 9$ and become fully extinct at $\mathrm{pH} 11$. The concentrations of hydroxyl ion species, which are very vital for magnetite forming reaction increases above $\mathrm{pH} 9$ and most of the ferrous ions exist as $[\mathrm{Fe}(\mathrm{OH})]^{+}$at a $\mathrm{pH}$ of 10.0 and as $\left[\mathrm{Fe}(\mathrm{OH})_{3}\right]^{-}$above $\mathrm{pH}$ 13.0. On the other hand, in the case of ferric ions, the presence of $\left[\left(\mathrm{Fe}^{3+}\right)\left(\mathrm{OH}^{-}\right)_{4}\right]^{-}$become predominant at $\mathrm{pH}$ above 8.5. Since the presence of ferrous and ferric ions is necessary for the formation of magnetite, the theoretical calculations of complex concentration as function of $\mathrm{pH}$ implied that the nucleation rate can be controlled by controlling the $\mathrm{pH}$ of the solution using alkali buffer solution. The details are discussed elsewhere. ${ }^{31)}$ The particle size decreased as the reaction $\mathrm{pH}$ was increased and this was corroborated by the fact that the saturation magnetization and the coercivity values were the least for particles with smaller diameter. ${ }^{31)}$ The variation in particle diameter is a function of the abundance of ferrous hydroxyl ions, which undergoes drastic variation in concentration in the $\mathrm{pH}$ range considered here. The ferrous hydroxyl ion concentration is lower at $\mathrm{pH} 9.5$ compared to $\mathrm{pH} 11.2$. Though ferrous ions also resides as $\mathrm{Fe}^{2+}$ and $\left(\mathrm{Fe}^{2+}\right)\left(\mathrm{SO}_{4}{ }^{2-}\right)$, they are not believed to have involved in the formation of the nucleus at $\mathrm{pH}$ of 9.5 and furthermore their concentrations decreases with increasing $\mathrm{pH}$. On the other hand, calculations also revealed that ferric ions mostly existed as $\left[\left(\mathrm{Fe}^{3+}\right)\left(\mathrm{OH}^{-}\right)_{4}\right]^{-}$at $\mathrm{pH}$ greater than 9.0 and their concentration remained almost constant in the $\mathrm{pH}$ range experimented. ${ }^{31)}$ Thus, the reason for the decrease in particle size at higher reaction $\mathrm{pH}$ could be explained by the formation of larger number of nucleus, since total amount of metal ion added in the solution is constant. The transmission electron microscope (TEM) images of the samples synthesized at $\mathrm{pH} 9.5$ and 11.2 are shown in Fig. 7. Though the gradual decrease in particle size with increasing reaction $\mathrm{pH}$ was observed, a clear difference was visible when the variation in solution $\mathrm{pH}$ was high. Even though the TEM measurements are confined to very small fraction of the sample, the magnetic properties such as saturation magnetization and coercivity also showed a gradual change with solution $\mathrm{pH}$.

The heating characteristics of magnetite samples prepared under pH 9.5 and 11.2 are shown in Fig. 8. It should be noted that the sample prepared at $\mathrm{pH} 11.2$ whose average diameter was only $12 \mathrm{~nm}$ exhibited the lower heating rate than the sample 

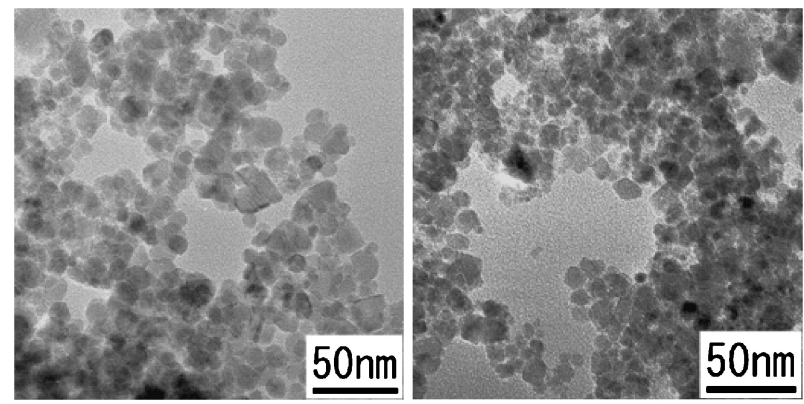

Fig. 7. The TEM images of omagnetite particles synthesized at $\mathrm{pH}$ values (a) 9.5 and (b) $11.2 .^{31)}$

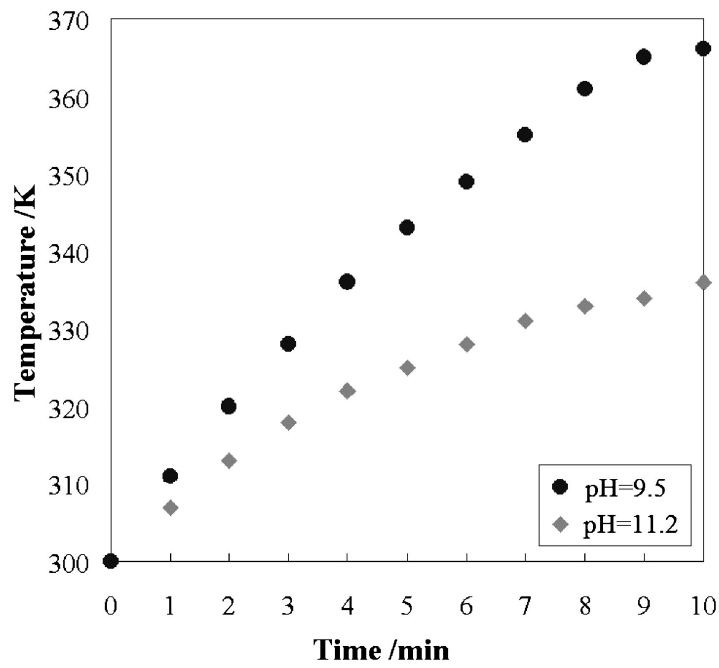

Fig. 8. Temperatures of the magnetite suspensions dispersing magnetite particles synthesized at $\mathrm{pH}$ (a) 9.5 and (b) 11.2 and exposed to ac magnetic field against exposure time $\left(H\right.$ and $f$ were $3.2 \mathrm{kAm}^{-1}$ and $600 \mathrm{kHz}$ ).

prepared at $\mathrm{pH} 9.5$, whose average diameter was $14 \mathrm{~nm}$. The maximum temperature recorded in 10 minutes AC magnetic field exposure were 336 and $367 \mathrm{~K}$ for samples prepared at $\mathrm{pH} 11.2$ and 9.5 respectively. On the other hand, the ESAR value was highest and $15.7 \mathrm{~W} \mathrm{~g}^{-1}$ for the sample with an average grain size of $13 \mathrm{~nm}^{31)}$ (prepared at $\mathrm{pH} 10$ ). This was comparable to the value reported by Hergt et al. ${ }^{32), 33)}$ However, it should be noted that the present technique has devised only the base for particle size control, and further effort is necessary to narrower the size distribution by using additional complex agents to achieve finer control over concentration of ferrous and ferric complex ions.

On the other hand, attempts have been made by several researchers to obtain monodispersed magnetite particles of different sizes by size classifying the particles synthesized by coprecipitation technique. Author has also contributed to this endeavor by preparing organic solvent based magnetite dispersion and subjecting them to different concentrations of bad solvent such as acetone and settling magnetite particles with large to small particle by increasing the concentration of bad solvent. ${ }^{34), 35)}$ Though the separation is not as sharp as the author would like it to be, it is much better than any of the synthesis process available to cater particles with diameter larger than $10 \mathrm{~nm}$. In the following section, the author describes the heat dissipation characterization of magnetite particles and discuss about the optimal properties of magnetite that is suitable for heat dissipation through Néel relaxation.

\section{Characteristics of magnetite particles that dissipates heat through Néel relaxation}

Magnetite particle that dissipates heat through Néel relaxation is ideal for magnetic hyperthermia for two specific reasons. Firstly, there will not be any discrepancies in heat dissipation characteristics of magnetite dispersion between in vitro and in vivo analysis. Secondly, the magnetite particle that dissipates heat through Néel relaxation is small enough to be brought into dispersion and could be used for targeted delivery, which is an additional advantage of magnetic fluid hyperthermia. Though there have been some reports pointing out that the heat dissipated is due to the contributions from both Brownian and Néel relaxations, there is hardly any report that tries to identify the physical properties of magnetite that generates heat mainly through Néel relaxation. In this section, we briefly describe the experiments carried out by the author to identify the optimum magnetite particle diameter that relaxes through Néel relaxation and their potential to be used in hyperthermia applications.

\subsection{Identification of relative contributions of Brownian and Néel relaxations}

The magnetite particles synthesized by coprecipitation method, coated with a surfactant, size classified and dispersed in water or oil contains particles that relax through both Néel and Brownian relaxations. The viscosity of the medium was controlled by adding a polymer in oil or dispersing particles in polyvinyl alcohol hydrogel ${ }^{36)}$ to delay or restrict the heat dissipation through Brownian relaxation.

Heat evolution experiments were carried out by introducing the suspensions dispersing 8 mass $\%$ of magnetite with different average particle diameter (samples A to E) into a test tube and by placing the same at the center of the solenoid coil that generated a magnetic field strength of $3.2 \mathrm{KA} \mathrm{m}^{-1}$ at $600 \mathrm{kHz} .{ }^{17)}$ The details of the experimental setup are given elsewhere. ${ }^{10)}$ The temperature of the magnetic suspension was measured using an optical fiber thermometer.

Physical characteristics of magnetite samples such as average particle diameter from TEM measurements, crystallite size from XRD analysis, blocking temperature from imaginary part of initial susceptibility as a function of temperature and ESAR considered in this study are shown in Table 1. Particle diameters of samples A to E are in the increasing order and the representative TEM images of samples A and E are shown in Fig. 9.

The results of heat dissipation experiments of samples A to E dispersed in water/low viscosity oil and high viscosity oil/ hydrogel are shown in Table 1. The ESAR value of the sample D dispersed in hydrogel was $16.8 \times 10^{-9} \mathrm{~W} \mathrm{~g}^{-1} \mathrm{Oe}^{-2} \mathrm{~Hz}^{-1}$, which is about $27 \%$ less than the one dispersed in water $\left(22.9 \times 10^{-9}\right.$ $\left.\mathrm{W} \mathrm{g}^{-1} \mathrm{Oe}^{-2} \mathrm{~Hz}^{-1}\right)$. The reduction in heat dissipation was due to the inability to generate of heat through particle rotation. Thus the ESAR value could be improved by using particles that have an average $T_{\mathrm{B}}$ less than R.T. and narrow particle size distribution. Similar results were also observed for the sample E. The ESAR of the sample $\mathrm{E}\left(29.5 \times 10^{-9} \mathrm{~W} \mathrm{~g}^{-1} \mathrm{Oe}^{-2} \mathrm{~Hz}^{-1}\right)$ was greater than that of the sample D. When viscosity was raised by dispersing in hydrogel, the ESAR of the sample E reduced by about $67 \%$ $\left(9.7 \times 10^{-9} \mathrm{~W} \mathrm{~g}^{-1} \mathrm{Oe}^{-2} \mathrm{~Hz}^{-1}\right)$ and the value was much lesser than that of the sample D. This suggests that the fraction of the particles that generated heat through Brownian rotation was comparatively large in sample E. These observations are also in line with the theoretical calculation (Fig. 3). The sample which had an average diameter below $13 \mathrm{~nm}$ had large fraction of 
Table 1. Particulate and magnetic properties of the samples ${ }^{17)}$

\begin{tabular}{|c|c|c|c|c|c|c|c|c|}
\hline \multirow{2}{*}{ Sample } & \multirow{2}{*}{$\begin{array}{c}\text { Average } \\
\text { diameter } \\
(\mathrm{nm})\end{array}$} & \multirow{2}{*}{$\begin{array}{c}\text { Standard } \\
\text { deviation } \\
(\mathrm{nm})\end{array}$} & \multirow{2}{*}{$\begin{array}{l}\text { Crystallite } \\
\text { size } \\
(\mathrm{nm})\end{array}$} & \multirow{2}{*}{$\begin{array}{c}T_{\mathrm{B}} \text { at } \\
600 \mathrm{kHz} \\
(\mathrm{K})\end{array}$} & \multicolumn{4}{|c|}{$\operatorname{ESAR}\left(10^{-9} \mathrm{~W} \mathrm{~g}^{-1} \mathrm{Oe}^{-2} \mathrm{~Hz}^{-1}\right)$} \\
\hline & & & & & Water & Water $+\mathrm{PVA}^{a}$ & Oil & Oil + Polymer \\
\hline A & 10.0 & 2.3 & 8.8 & 64.1 & $\mathrm{n} / \mathrm{a}$ & $\mathrm{n} / \mathrm{a}$ & 0.8 & 0.8 \\
\hline B & 11.6 & 2.7 & 9.2 & 140.7 & $\mathrm{n} / \mathrm{a}$ & $\mathrm{n} / \mathrm{a}$ & 6.7 & 6.0 \\
\hline C & 13.9 & 3.4 & 11.0 & 220.9 & $\mathrm{n} / \mathrm{a}$ & $\mathrm{n} / \mathrm{a}$ & 16.4 & 15.8 \\
\hline $\mathrm{D}$ & 12.5 & 2.9 & 13.4 & 271.4 & 22.9 & 16.8 & $\mathrm{n} / \mathrm{a}$ & $\mathrm{n} / \mathrm{a}$ \\
\hline $\mathrm{E}$ & 15.7 & 4.4 & 13.2 & $\mathrm{n} / \mathrm{a}$ & 29.5 & 9.7 & $\mathrm{n} / \mathrm{a}$ & $\mathrm{n} / \mathrm{a}$ \\
\hline
\end{tabular}

${ }^{a}$ Polyvinyl alcohol

n/a: not available
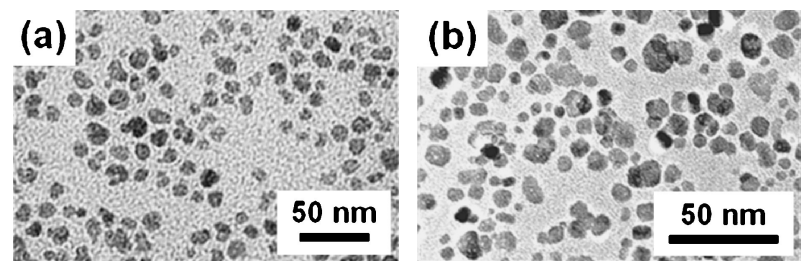

Fig. 9. TEM images of the samples. (a) sample A, and (b) sample E. ${ }^{17)}$

particles relaxing through Néel mechanism. Thus, the waterdispersed magnetite sample D was used to verify the heating potential in the in vitro experiments using microphage cells.

\subsection{Evaluation of the heating potential of magnet- ite particles that dissipates heat mainly through Néel Relaxation}

The thermal dissipation potential of the particles that dissipate heat through Néel relaxation was examined by carrying out in vitro experiments using macrophage (RAW 264.7). Water dispersed magnetite particles were introduced into culture fluid (D-MEM, Sigma) after filtering and sterilizing the same. Then, the particle concentration was adjusted to $1.0 \mathrm{mg} / \mathrm{mL}$ and about $7.5 \times 10^{6}$ of RAW 264.7 was introduced into the culture media and cultured at $310 \mathrm{~K}$. After centrifuging the suspension at $1000 \mathrm{G}$ for $5 \mathrm{~min}$, magnetite uptaken cell and free magnetite were separated. The calorimetric analysis using potassium thiocyanate was carried out to evaluate the $\mathrm{Fe}^{3+}$ uptake concentration per cell. And also, the macrophage was exposed to various concentrations of magnetite for different durations to obtain macrophage with different loads of magnetite particles. Then, about $1.5 \times 10^{7}$ of RAW 264.7 containing culture media with different magnetite uptake concentrations were exposed to the $\mathrm{AC}$ magnetic field to measure the temperature rise against time.

The magnetite uptake by RAW cell was a function of time and saturated after $24 \mathrm{~h}$. Furthermore, the uptake was also a function of the magnetite particle concentration of the culture media and increased with increased initial concentration. Figure 10 shows the optical images of (a) RAW cells and (b) cells incubated with magnetite particles. After incubation with magnetite particles, the color of RAW cells changed from colorless to black. This clearly indicated the phagocytosis of RAW cells.

Figure 11 shows the temperature rise of the cell suspension with different concentrations of magnetite uptake. The cell suspension containing magnetite nanoparticles exhibited a temperature rise of 8 degrees and above depending on the magnetite particle concentration after an exposure time of $30 \mathrm{~min}$. This suggests that the magnetite uptake concentration was adequate to raise the temperature of targeting tissue above $316 \mathrm{~K}$ and confirms the potential of nearly superparamagnetic
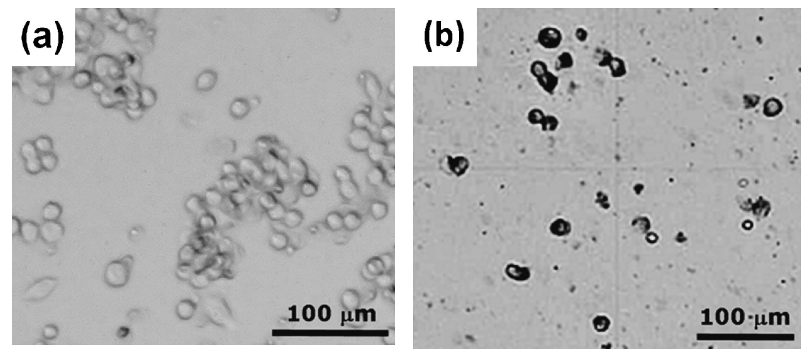

Fig. 10. Optical micrograph of RAW264.7 cells. (a) before, and (b) after introducing magnetite nanoparticles.

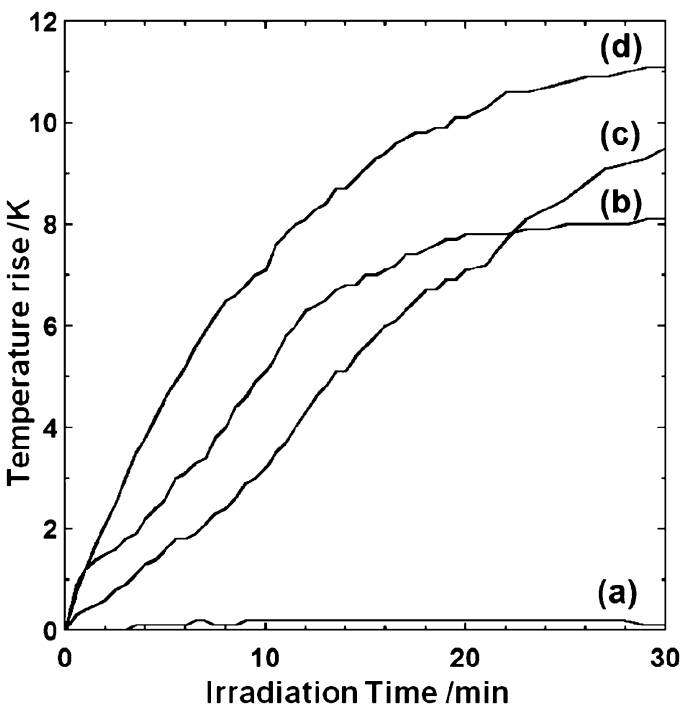

Fig. 11. Temperature rise of the cell suspension with different concentrations of magnetite uptake. (a) $0.0 \mathrm{mg} / \mathrm{mL}$, (b) $1.55 \mathrm{mg} / \mathrm{mL}$, (c) $3.62 \mathrm{mg} / \mathrm{mL}$, and (d) $5.58 \mathrm{mg} / \mathrm{mL}$.

particles for effective use in hyperthermia treatment. Since the experiments were carried out at R.T., the temperature of the cell suspension reached was not adequate to thermal necrosis. However, the death of RAW cell was experimentally verified by exposing $1.0 \mathrm{~mL}$ of culture fluid containing about $2.5 \times 10^{6}$ cell $/ \mathrm{mL}$ in a closed vessel to hot bath maintained at $316 \mathrm{~K}$ for $15 \mathrm{~min}$ to $2 \mathrm{~h}$. The cell death rate was determined by using the trypan blue staining test. The RAW cell death rate reached $100 \%$ in samples exposed to $316 \mathrm{~K}$ for $1 \mathrm{~h}$ and an elapsed time of $24 \mathrm{~h}$. However, it should be noted that unlike the RAW cells the cancer cells will not easily uptake magnetite unless the surface of these particles are suitably modified to facilitate efficient uptake. Thus working towards surface modification of each individual particle to facilitate the uptake by melanoma cancer cells is necessary. 
On the other hand, recent reports have claimed the effectiveness of MFH in treating prostate cancer and glioblastoma. ${ }^{37)-39)}$ However, details pertaining to some basic information, such as (a) the optimum particle diameter, (b) magnetic nanoparticles (MNPs) concentration necessary to elevate the temperature of the target volume above $316 \mathrm{~K}$ and also (c) the temperature distribution inside and outside the target region, are limited. The above information is vital to provide required level of therapeutic temperature with minimum magnetic particle concentration and also to avoid damage of the surrounding normal tissue through overheating. In the next section, we discuss about the heat diffusion characteristic of magnetite nanoparticles that dissipates heat by Néel relaxation by dispersing the magnetite particles in hydrogel.

\section{Heat diffusion characteristics of magnetite}

According to the guidelines of the international non-ionizing radiation security council, the over current density value for professional exposure has been set at $f / 100 \mathrm{~mA} \mathrm{~m}^{-2}$ to protect its influence on nerves in the head and body. At the same time, from the body temperature point of view, the SAR of the entire body and local areas (hands and legs) has been limited to 0.4 and $20 \mathrm{~W} \mathrm{~kg}^{-1}$ respectively. When an exposure of circular cylinder body with a diameter of $0.15 \mathrm{~m}$ and electric conductivity of $0.2 \Omega^{-1} \mathrm{~m}^{-1} \mathrm{kA} \mathrm{m}^{-1}$ is assumed, independent of frequency, the entire body could be exposed to $H_{a c}<0.1 \mathrm{kA} \mathrm{m}^{-1}$ and the body parts such as hand or leg is generally limited to a value corresponding to $H_{a c} \cdot f<5 \times 10^{8} \mathrm{~A} \mathrm{~m}^{-1} \mathrm{~s}^{-1}{ }^{40)}$ As a result, as far as we accede by the magnetic field strength guidelines, the response of magnetic vector cannot be anticipated and effective hyperthermia becomes difficult. However, if we consider the over current density in transcranial magnetic stimulation (TMS) that reaches few tens of $\mathrm{A} \mathrm{m}^{-2}$ and the placidity of the influence of current at frequencies above $10 \mathrm{kHz}$, for therapeutic purpose, there is no reason for us to stick to the present standards. ${ }^{41)}$ On the other hand, since the body temperature can be controlled by shortening the exposure time, there is no necessity to accede to the limiting value of SAR. If anything, the temperature difference between the cancer tissue containing magnetic particles and the normal tissue should be considered seriously. Thus, the heat diffusion characteristics of the magnetite particles become very vital. Andrä et $\mathrm{al}^{42}$ ) numerically estimated the heat diffusion characteristics of constant power density spherical heat source surrounded by a homogeneous heat conductive media and also experimentally verified the same by dispersing micron-sized MNP in the cylindrical muscle tissue of cow. They reported a reasonable agreement between numerical estimation and experimental observation. ${ }^{42)}$ However, it should be noted that the heating mechanism in the above study was different to the one in MFH. On the other hand, Hergt et al. ${ }^{5)}$ numerically estimated the temperature distribution in a spherical heat source dispersing MNP. And also, they investigated non-spherical and spherical shaped organic gel models experimentally. However, their experimental study was limited to measuring the temperature at the surface of the heat source. Recently, Wang et al. ${ }^{43)}$ assessed the heating effect in vivo by preparing magnetite suspension dispersing particles with various average diameters. Though they found that MNP can generate enough power for effective MFH, information on the physical properties of the particles such as size distribution, blocking temperature, etc. were not reported. The author undertook a study to investigate the concentration dependence of heat diffusion characteristics of MNP numerically and experimentally using a spherical heat

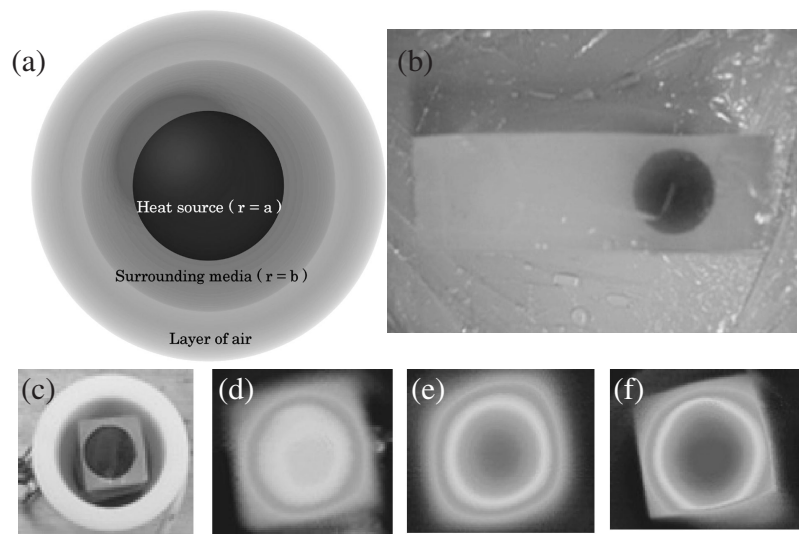

Fig. 12. (a) Numerical model (The length of $a, b$ and $R$ are $12.5 \mathrm{~mm}$, $20.11 \mathrm{~mm}, 1 \mathrm{~m}$ respectively) and photographs of (b) experimental specimen (spherical heat source dispersing magnetite in hydrogel, covered with magnetite-free hydrogel), (c) cross-section of heat source placed inside the coil and (d)-(e) thermal views of the specimen exposed to varying $\mathrm{AC}$ magnetic field exposure time. ${ }^{44)}$

source (diameter: $25 \mathrm{~mm}$ ) dispersing MNPs of various weight fractions (average particle diameter: $13.5 \mathrm{~nm}$ ) in hydrogel surrounded by magnetite free hydrogel simulating cancer and normal tissues respectively. ${ }^{44)}$

A numerical model was constructed to calculate the onedimensional heat diffusion characteristics of the heat source dispersing MNPs in hydrogel are shown in Fig. 12(a). The heat source (radius of $a=12.5 \mathrm{~mm}$ ) in an alternating magnetic field is assumed to dissipate constant power. And also, the magnetite dispersed spherical heat source is assumed to be surrounded by particle free hydrogel $(a<r<b)$. Additionally, the above spherical composite (magnetite dispersed hydrogel and magnetite free hydrogel) sphere is surrounded by a layer of air $(b<r<R)$. The radius of $b$ and $R$ is effective radius calculated by the following Eq. (7).

$$
r=3 \times \frac{\text { Volume }}{\text { Surface area }}
$$

The radius of $b$ and $R$ are 21.1 and $31.0 \mathrm{~mm}$ respectively.

The governing equations for the one-dimensional heat diffusion are as follows.

$$
\begin{aligned}
& \rho c \frac{\partial T_{1}}{\partial t}=\frac{1}{r^{2}} \frac{\partial}{\partial r}\left(k r^{2} \frac{\partial T_{1}}{\partial t}\right)+Q \quad(0<r<a) \\
& \rho c \frac{\partial T_{2}}{\partial t}=\frac{1}{r^{2}} \frac{\partial}{\partial r}\left(k r^{2} \frac{\partial T_{2}}{\partial t}\right) \quad(a<r<b) \\
& \rho c \frac{\partial T_{3}}{\partial t}=\frac{1}{r^{2}} \frac{\partial}{\partial r}\left(k r^{2} \frac{\partial T_{3}}{\partial t}\right) \quad(b<r<R)
\end{aligned}
$$

$\rho$ : density of mass, $c$ : specific heat, $k$ : heat conductivity, $r$ : distance from the center of heat source (sphere dispersing MNP), $T$ : temperature $\left(T_{1}\right.$ : temperature in the heat source, $T_{2}$ : temperature in the surrounding media, $T_{3}$ : temperature in the layer of air), $Q$ : heat evolution

The initial and boundary conditions were assumed as follows:

$$
\begin{aligned}
& T_{1}(r, 0)=T_{2}(r, 0)=T_{3}(r, 0)=T_{e} \\
& \left(\frac{\partial T_{1}}{\partial r}\right)=0 \\
& \left(\frac{\partial T_{1}}{\partial r}\right)=\left(\frac{\partial T_{2}}{\partial r}\right) \quad(r=a)
\end{aligned}
$$


Table 2. Physical and thermal properties of tissues

\begin{tabular}{|c|c|c|c|c|c|c|}
\hline Medium & $\begin{array}{c}\text { Concentration } \\
\text { of MNPs* } \\
(\operatorname{mass} \%) \\
\end{array}$ & $\begin{array}{c}\text { Thermal } \\
\text { conductivity } \\
k\left(\mathrm{~W} \mathrm{~m}^{-1} \mathrm{~K}^{-1}\right) \\
\end{array}$ & $\begin{array}{l}\text { Specific heat } \\
\text { capacity } \\
c\left(\mathrm{~J} \mathrm{~kg}^{-1} \mathrm{~K}^{-1}\right)\end{array}$ & $\begin{array}{c}\text { Mass } \\
\text { density } \\
\rho\left(\mathrm{g} \mathrm{m}^{-3}\right) \\
\end{array}$ & $\begin{array}{c}\text { Heat dissipation } \\
\text { rate } \\
Q_{\mathrm{m}}\left(\mathrm{W} \mathrm{cm}^{-3}\right)\end{array}$ & $\begin{array}{c}\text { Perfusion } \\
\text { rate } \\
W\left(10^{-3} \mathrm{~m}^{3} \mathrm{~m}^{-3} \mathrm{~s}^{-1}\right) \\
\end{array}$ \\
\hline Blood & $\mathrm{n} / \mathrm{a}$ & 0.51 & 3720 & 1.060 & $\mathrm{n} / \mathrm{a}$ & $\mathrm{n} / \mathrm{a}$ \\
\hline Brain & $\mathrm{n} / \mathrm{a}$ & 0.54 & 3640 & 1.040 & $\mathrm{n} / \mathrm{a}$ & $\mathrm{n} / \mathrm{a}$ \\
\hline Polystyrene & $\mathrm{n} / \mathrm{a}$ & 0.10 & 1260 & 0.105 & $\mathrm{n} / \mathrm{a}$ & $\mathrm{n} / \mathrm{a}$ \\
\hline Prostate & $\mathrm{n} / \mathrm{a}$ & 0.50 & 3600 & 1.050 & $\mathrm{n} / \mathrm{a}$ & 10.2 \\
\hline PVA hydro-gel & $\mathrm{n} / \mathrm{a}$ & 0.2536 & 2759 & 1.000 & $\mathrm{n} / \mathrm{a}$ & $\mathrm{n} / \mathrm{a}$ \\
\hline \multirow{3}{*}{ PVA hydro-gel + MNPs } & 1.0 & 0.2882 & 2995 & 1.001 & 0.0844 & $\mathrm{n} / \mathrm{a}$ \\
\hline & 2.0 & 0.3043 & 3197 & 1.009 & 0.1704 & $\mathrm{n} / \mathrm{a}$ \\
\hline & 4.0 & 0.3683 & 2786 & 1.026 & 0.3466 & $\mathrm{n} / \mathrm{a}$ \\
\hline
\end{tabular}

*Magnetite nanoparticles.

n/a: not available

The physical and thermal properties of brain and blood are taken from Ref. 45)

$$
\left(\frac{\partial T_{2}}{\partial r}\right)=\left(\frac{\partial T_{3}}{\partial r}\right) \quad(r=b)
$$

$T_{\varepsilon}$ : initial temperature $(290.15 \mathrm{~K})$. The $\rho, c$ and $k$ of magnetite dispersed hydrogel are measured by using Archimedes, differential scanning calorimetry (DSC) and unsteady hot wire methods, respectively. The results are shown in Table 2. Calculation was performed by digitizing Eq. (8a), (8b), (8c) by using the complete implicit method and solving by tri-diagonal matrix algorithm.

On the other hand, in the experimental investigation, in accordance with the numerical model, $25 \mathrm{~mm}$ diameter spherical heat source dispersing double surfactant layered MNPs was prepared. The magnetite particles suitable for hyperthermia should dissipate heat through Néel relaxation, which does not depend on the viscosity of the local environment. Thus, the particles were dispersed in hydrogel, which inhibits the rotation of the magnetite particles exposed to ac magnetic field and simulates the worst situation that may prevail in vivo. The photograph of the experimental specimen, cross-section of heat source (hydrogel dispersing magnetite) surrounded by magnetite free hydrogel placed inside the coil are shown in Figs. 12(b) and (c). Then, the thermal views of the specimen exposed to varying AC magnetic field exposure time are shown in Figs. 12(d)-(f). Heat source dispersing 1, 2, 4 mass \% of magnetite were prepared and the heat diffusion characteristics of the MNP was determined by placing the specimen inside the coil and exposing the same to AC magnetic field strength and frequency of $3.2 \mathrm{kA} \mathrm{m}^{-1}$ and $600 \mathrm{kHz}$ respectively.

The calculated as well as experimentally observed temperature rise is shown in Fig. 13. The initial temperature was set at $290 \mathrm{~K}$ to compare the numerical and experimental values. Since the cancer tissue is claimed to become necrotic at $316 \mathrm{~K}$, the temperature should be raised only by 6-7 degrees above body temperature. Hence, the results indicated that 2 mass \% magnetite is sufficient for therapy, if metabolism and blood perfusion are ignored. Additionally, the temperature at a distance of $15 \mathrm{~mm}$ from the center of the heat source was much lower than that the surface and the local heating characteristics of MFH was confirmed. The disparity in temperature distribution between the numerical calculation and experimental observation was due to the difference between the actual particles size distribution and the one estimated from the TEM measurements. In MFH treatment, minimum use of MNP concentration is desirable. This could be achieved by using MNP with optimum diameter with narrow size distribution. Considering the fact that the temperature necessary to be maintained within the cancer tissue should

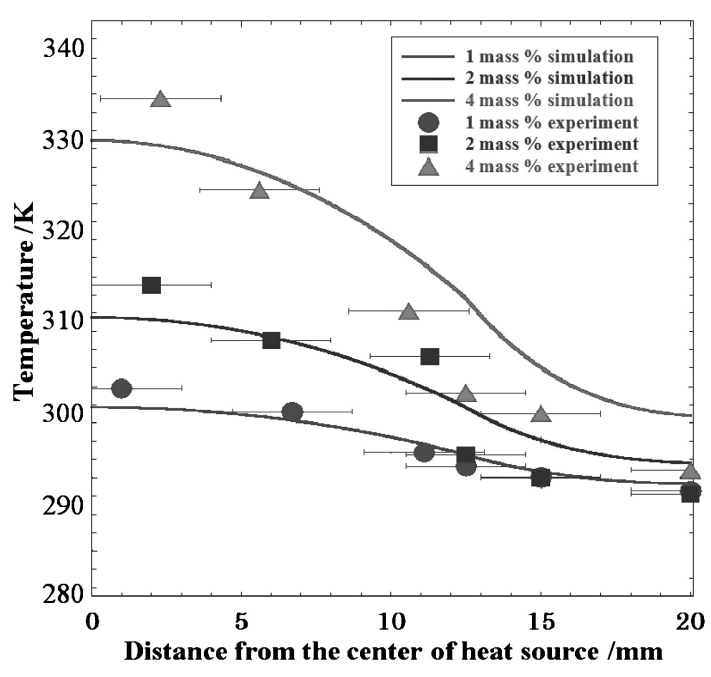

Fig. 13. Comparison between numerically estimated and experimentally observed temperature distributions. ${ }^{44)}$

be higher than $316 \mathrm{~K}$, and blood perfusion that removes part of the heat generated away, at least 2 mass $\%$ of magnetite is necessary to raise the temperature in a $12.5 \mathrm{~mm}$ diameter sphere. However, it should be noted that the physical properties of hydrogel such as specific heat, heat conductivity, mass density, etc. are different from the human cells. The above numerical and experimental studies on MFH have suggested that the existing theories proposed for heat generation and dissipation could be used to extend this model to analyze the temperature distribution considering blood flow in cancer tissues. Thus we extended the calculation model to incorporate the intravital factors such as blood flow, metabolism to arrive at biologically significant conclusions.

To simulate the temperature distribution in the experimental specimen, FLUENT version 6.3.26 (ANSYS Inc.) was used in the present study. The implicit solver for solid phase was employed. Figure 14 shows a computational domain in the present study.

The computational domain consists of three zones: 1) outer cylindrical zone; 2) inner square prismatic zone; and 3) spherical zone. Each zone respectively corresponds to insulator (polystyrene), PVA hydrogel, and PVA hydrogel dispersing magnetite nanoparticles in the experiments. Thermal conductivity, specific heat capacity, and mass density of each material ${ }^{45)}$ are shown in Table 2. 


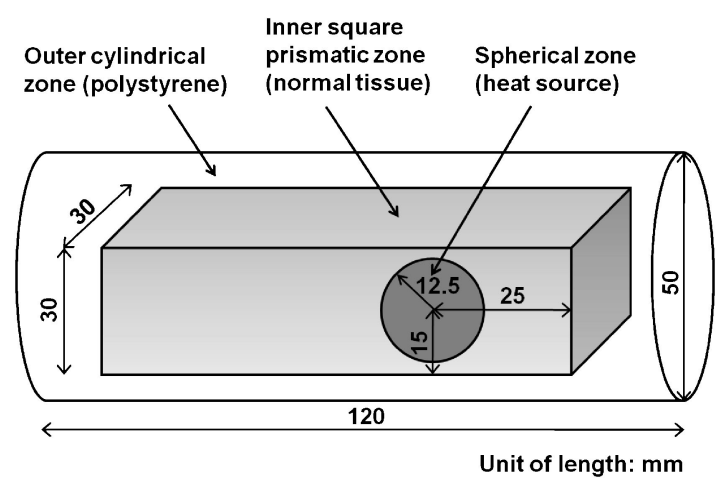

Fig. 14. Scheme of the computational domain.

Values of heat release rate at different concentrations of nanoparticles are also shown in Table 2 and added to the energy equation in the spherical zone as heat source term. Temperature at outer surface of the outer cylindrical zone was fixed at $290 \mathrm{~K}$. Initial temperatures of all three zones were set to $290 \mathrm{~K}$. Unstructured tetrahedral mesh was constructed using fluid analysis processor (GAMBIT). The numbers of element of the outer cylindrical zone, inner square prismatic zone, and spherical zone were $1,060,723,600,148$, and 62,289 , respectively.

Both the experimental and computational temperatures decrease with an increase of the distance from the center of heat source. The experimental temperatures near the center of heat source are in good quantitative agreement with the computational temperatures for different concentrations of nanoparticles. The experimental temperature profiles for nanoparticle concentrations of 1.0 and 2.0 mass \% quantitatively agreed with the computational values (figure not shown). On the other hand, the observed temperature for a nanoparticle concentration of 4.0 mass $\%$ was lower than that of the computed value. This is due to the contamination of bubbles in the gap between the spherical heat source and surrounding PVA hydrogel.

To predict the temperature distribution in biological body, three computational zones are regarded as blood, organ, and tumor, respectively. Then, two terms were added to the energy equation as follows:

$$
\rho_{\mathrm{t}} c_{\mathrm{t}} \frac{\partial T}{\partial t}=\operatorname{div}(k \operatorname{grad} T)+W \rho_{\mathrm{b}} c_{\mathrm{b}}\left(T_{\mathrm{a}}-T\right)+Q_{\mathrm{met}}+Q_{\mathrm{m}}
$$

Where $W, T_{\mathrm{a}}, Q_{\mathrm{met}}, Q_{\mathrm{m}}$ are blood flow rate, temperature of arterial blood, metabolic heat generation $\left.\left(33.8 \mathrm{kWm}^{-3}\right),{ }^{46}\right)$ and heat dissipation of MNPs, respectively. Subscripts of $t$ and $b$ indicate tissue and blood, respectively. In the present study, two cases of application are considered: prostate and brain. Computational parameters are shown in Table 2.

Figure 15 shows the temperature profiles of simulated tissue dispersing various concentrations of MNPs. The temperature decreases with increasing the distance from the center of the heat source. The temperature significantly decreased at the distance of $12.5 \mathrm{~mm}$ that corresponded to the boundary between spherical heat source and the outer hydrogel. Judging from the calculated profile, 2 mass \% of MNPs concentration is needed to maintain the brain tissue at $316 \mathrm{~K}$, while prostate requires 2.5 mass \% of MNPs concentration for the thermal therapy due higher blood flow rate in the prostrate than that in the brain. This indicates that the estimation of blood flow rate is an important factor for MFH treatment. It should be noted that the physical properties of normal tissues were used in the numerical estima-

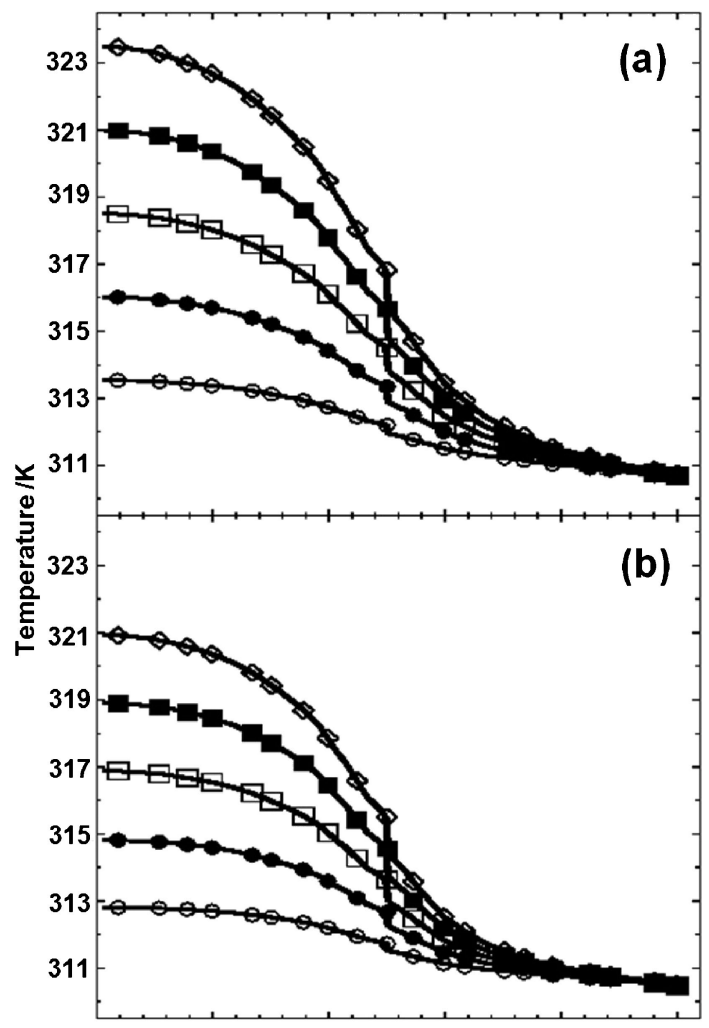

Distance from the center of heat source $/ \mathrm{mm}$

Fig. 15. Results of temperature simulation of tissues dispersing various concentrations of MNPs after exposing AC magnetic field for $600 \mathrm{sec}$. (a) brain, and (b) prostate. Open circle: 0.5 mass $\%$, solid circle: 1.0 mass $\%$, open square: 1.5 mass $\%$, solid square: 2.0 mass $\%$, and open diamond: 2.5 mass $\%$.

tion, even though the vascular network is not well developed in tumor tissues. Thus, the incorporation of modeling parameters such as physical properties of tumor, blood flow rate during MFH treatment will enable us to obtain more accurate results.

\section{Prospects of magnetic fluid hyperthermia}

In this review, the main focus has been on the progress of theoretical and experimental investigations towards the realization of MFH through the heat dissipated by the Néel relaxation of magnetite particles. The intension behind this is the fact that the particles that dissipate heat do not depend on the local conditions of the living organism and also they are of the right size range to be used in drug targeting. However, it should be noted that the criterion for the selection of particle size is not only governed by the above factors, but also on specific applications and the operational limits of alternating magnetic field generators. As a matter of fact, at present, the exact mechanism suitable for hyperthermia cancer treatment is not known. And also, the right size of the magnetic particles suitable for the above is also not known. In fact, the answer to this simple question is not available in literature. One of the reasons for the same is that most of the discussion is based on calculated power of heat dissipation obtained separately either using the imaginary part of the ac susceptibility of superparamagnetic phenomena or forced reversal and rotation of the static magnetic hysteresis. Therefore, it was difficult to compare the results reciprocally. However, when the working magnetic field is applied at temperatures suitable for magnetic hyperthermia, the driving 
forces such as superparamagnetic and magnetic torque for reversal and rotation of magnetic vector cannot be ignored, and the present evaluation is not necessarily suitable. Furthermore, there is a need for a comprehensive analysis to establish effective utilization of the difference between magnetic reversal and particle rotation.

While research efforts toward basic understanding is in progress by various groups in different countries, a group in Germany has made a step forward by applying MFH for human patients and have claimed reasonable success in direct injection therapy. However, targeted hyperthermia following intravenous injection is still undergoing strenuous development. Author believes that though the progress in application oriented research is necessary, continuation of research on fundamentals are also equally important. The success in the establishment of MFH therapy lies very much on the integrated approach considering both the physical constraints of the thermal seeds and practically feasible alternating magnetic field generators and also devising case specific treatment techniques.

\section{References}

1) P. Wust, B. Hildebrandt, G. Sreenivasa, B. Rau, J. Gellermann, H. Riess, R. Felix and P. M. Schlag, Lancet Oncol., 3, 487-489 (2002).

2) P. Moroz, S. K. Jones and B. N. Gray, J. Surg. Oncol., 77, 259269 (2001).

3) R. K. Gilchrist, R. Medal, W. D. Shorey, R. C. Hanselman, J. C. Parrott and C. B. Taylor, Ann. Surg., 146, 596-606 (1957).

4) H. Matsuki, T. Yanada, T. Sato, K. Murakami and S. Minakawa, Mater. Sci. Eng., A, 181-182, 1366-1368 (1994).

5) R. Hergt, W. Andra, C. d'Ambly, I. Hilger, W. Kaiser, U. Richter and H. Schmidt, IEEE Trans. Magn., 34, 3745-3754 (1998).

6) M. Shinkai, M. Yanase, M. Suzuki, H. Honda, T. Wakabayashi, J. Yoshida and T. Kobayashi, J. Magn. Magn. Mater., 194, 176-184 (1999).

7) A. Jordan, R. Scholz, P. Wust, H. H. Fähling and R. Felix, J. Magn. Magn. Mater., 201, 413-419 (1999).

8) A. Jordan, R. Scholz, K. Maier-Hauff, M. Johannsen, P. Wust, J. Nadobny, H. Schirra, H. Schmidt, S. Deger, S. Loening, W. Lanksch and R. Felix, J. Magn. Magn. Mater., 225, 118-126 (2001).

9) R. Müller, R. Hergt, M. Zeisberger and W. Gawalek, J. Magn. Magn. Mater., 289, 13-16 (2005).

10) T. Atsumi, B. Jeyadevan, Y. Sato and K. Tohji, J. Magn. Soc. Jpn., 30, 555-560 (2006).

11) G. F. Goya, R. Fernandez-Pacheco, M. Arruebo, N. Cassinelli and M. R. Ibarra, J. Magn. Magn. Mater., 316, 132-135 (2007).

12) T. Atsumi, B. Jeyadevan, Y. Sato and K. Tohji, J. Magn. Magn. Mater., 310, 2841-2843 (2007).

13) L.-Y. Zhang, H.-C. Gu and X.-M. Wang, J. Magn. Magn. Mater., 311, 228-233 (2007).

14) J.-P. Fortin, C. Wilhelm, J. Servais, C. Ménager, J.-C. Bacri and F. Gazeau, J. Am. Chem. Soc., 129, 2628-2635 (2007).

15) C. Dennis, A. J. Jackson, J. A. Borchers, R. Ivkov, A. R. Foreman, J. W. Lau, E. Goernitz and C. Gruettner, 52nd Annual Conference on Magnetism and Magnetic Materials, Nov. 5-9, Tampa, Florida, (2007) p. 29.

16) R. E. Rosensweig, J. Magn. Magn. Mater., 252, 370-374 (2002).

17) M. Suto, Y. Hirota, M. Mamiya, A. Fujita, R. Kasuya, K. Tohji and B. Jeyadevan, J. Magn. Magn. Mater., 321, 1493-1496 (2009); M. Suto, Y. Hirota, M. Mamiya, R. Kasuya, A. Fujita, K. Tohji and B. Jeyadevan, J. Magn. Soc. Jpn., 33, 391-395
(2009).

18) J.-P. Fortin, F. Gazeau and C. Wilhelm, Eur. Biophys. J., 37, 223-228 (2008).

19) T. Sato, IEEE Trans. Magn., 6, 795-799 (1970).

20) S. Sun and H. Zeng, J. Am. Chem. Soc., 124, 8204-8205 (2002).

21) T. Sugimoto and E. Matijević, J. Colloid Interface Sci., 74, 227-243 (1980).

22) M. Tada, S. Hatanaka, H. Sanbonsugi, N. Matsushita and M. Abe, J. Appl. Phys., 93, 7566-7568 (2003).

23) J. Park, K. An, Y. Hwank, J. E. G. Park, H. J. Noh, J. Y. Kim, J. H. Park, N. M. Hwang and T. Hyeon, Nat. Mater., 3, 891895 (2004)

24) W. W. Yu, J. C. Falkner, C. T. Yavuz and V. I. Colvin, Chem. Commun. (Camb.), 2306-2307 (2004).

$25)$ J. Cheon, N. J. Kang, S. M. Lee, J. H. Lee, J. H. Yoon and S. J. Oh, J. Am. Chem. Soc., 126, 1950-1951 (2004).

26) B. Jeyadevan, T. Atsumi, M. Suto, R. Kasuya, Y. Sato and K. Tohji, Therm. Med., 25, 43-52 (2009).

27) T. Hosono, H. Takahashi, Y. Sato, K. Tohji and B. Jeyadevan, AIP Conf. Proc., 898, 135-137 (2007).

28) F. Vereda, J. Vicente, M. P. Morales, F. Rull and R. H. Avarez, J. Phys. Chem. C, 112, 5843-5849 (2008).

29) D. K. Kim, M. Mikhaylova, Y. Zhang and M. Muhammed, Chem. Mater., 15, 1617-1627 (2003).

30) M. Mikhaylova, D. K. Kim, N. Bobrysheva, M. Osmolowsky, V. Semenov, T. Tsakalakos and M. Muhammed, Langmuir, 20, 2472-2477 (2004).

31) T. Hosono, H. Takahashi, A. Fujita, R. Justin Joseyphus, K. Tohji and B. Jeyadevan, J. Magn. Magn. Mater., 321, 30193023 (2009).

32) R. Hergt, W. Andra, C. G. D’ Ambly, I. Hilger, W. A. Kaiser, U. Richter and H.-G. Schmidt, IEEE Trans. Magn., 34, 37453754 (1998).

33) R. Hergt, R. Hiergeist, I. Hilger, W. A. Kaiser, Y. Lapatnikov, S. Margel and U. Richter, J. Magn. Magn. Mater., 270, 345347 (2004).

34) H. Sasaki, O. J. P. Perez, B. Jeyadevan, K. Tohji and A. Kasuya, J. Jpn. Soc. Powder Powder Metall., 49, 135-140 (2002).

35) O. Perales-Perez, H. Sasaki, A. Kasuya, B. Jeyadevan, K. Tohji, T. Hihara and K. Sumiyama, J. Appl. Phys., 91, 69586960 (2002).

36) M. Ohta, A. Handa, H. Iwata, D. A. Rüfenacht and S. Tsutsumi, Technol. Health Care, 12, 225-233 (2004).

37) M. Johannsen, U. Gneveckow, A. Feussner, L. Eckelt, N. Waldöfner, R. Scholz, S. Deger, P. Wust, S. A. Loening and A. Jordan, Int. J. Hyperthermia, 21, 637-647 (2005).

38) M. Johannsen, U. Gneveckow, B. Thiesen, K. Taymoorian, C. Cho, N. Waldöefner, S. Scholz, A. Jordan, S. Loening and P. Wust, Eur. Urol., 52, 1653-1662 (2006).

39) K. Maier-Hauf, R. Rothe, R. Scholz, U. Gneveckow, P. Wust, B. Thiesen, A. Feussner, A. Deimling, N. Waldöfner, R. Felix and A. Jordan, J. Neurooncol., 81, 53-60 (2007).

40) Guidelines for Limiting Exposure to Time-Varying Electric, Magnetic, and Electromagnetic Fields (up to $300 \mathrm{GHz}$ ). Health Phys., 74, 494-522 (1998).

41) H. Mamiya and B. Jeyadevan, Annual Meeting of Japanese Magnetic Fluid Association (2009) p. 18.

42) W. Andrä, C. G. d'Ambly, R. Hergt, A. Hilger and W. A. Kaiser, J. Magn. Magn. Mater., 194, 197-203 (1999).

43) X. Wang, H. Gu and Z. Yang, J. Magn. Magn. Mater., 293, 334-340 (2005).

44) M. Suto, H. Kosukegawa, K. Maruta, M. Ohta, K. Tohji and B. Jeyadevan, J. Magn. Magn. Mater., 321, 3483-3487 (2009).

45) G. Brix, M. Seebass, G. Hellwig and J. Griebel, Magn. Reson. Imaging, 20, 65-76 (2002).

46) Y. Rabin and A. Shitzer, J. Biomech. Eng., 120, 32-37 (1998). 


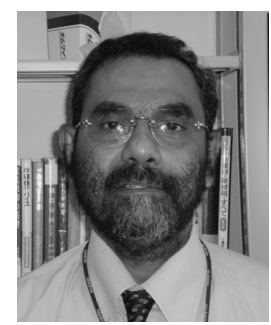

Balachandran Jeyadevan Graduated from Moratuwa University, Sri Lanka in 1980. Obtained M. Eng. from Moratuwa University in 1987 and Ph. D from Tohoku University in 1994. Worked as a Research Associate in Tohoku University from April, 1994 till June, 1996, Lecturer in Akita University from July, 1996 till September, 1999, Associate Professor in Tohoku University from October, 1999 till March, 2006, Professor in Tohoku University from April, 2006 till March, 2010. Professor at The University of Shiga Prefecture since April, 2010. 